\title{
Activation of cAMP Signaling Facilitates the Morphological Maturation of Newborn Neurons in Adult Hippocampus
}

\author{
Takashi Fujioka, Aya Fujioka, and Ronald S. Duman \\ Division of Molecular Psychiatry, Abraham Ribicoff Research Facilities, Connecticut Mental Health Center, Yale University School of Medicine, New Haven, \\ Connecticut 06508
}

\begin{abstract}
Previous studies have demonstrated that activation of the cAMP cascade, including the cAMP response element-binding protein (CREB), increases the proliferation and survival of newborn neurons in adult mouse hippocampus. In the present study, we determined whether the cAMP-CREB cascade also influences the morphological maturation of newborn neurons in the subgranular zone of the hippocampus. Rolipram, a selective inhibitor of the cAMP-specific phosphodiesterase type 4, was administered to activate the cAMP cascade, and neuronal morphology was determined by analysis of Golgi-impregnated neurons in the subgranular zone of hippocampus. Rolipram administration significantly increased the number of branch points and length of dendrites relative to vehicle treatment. Increased branch number and length were accompanied by increased levels of phosphorylated CREB, the active form of this transcription factor, in immature neurons. In contrast, the morphology of Golgi-impregnated neurons was not significantly influenced by rolipram treatment in inducible transgenic mice expressing a dominant-negative mutant of CREB in hippocampus. We also tested the influence of cAMP analogs in primary hippocampal cultures and found that activation of the cAMP pathway increased and inhibition of the cAMP cascade decreased the number of branches and length of processes as observed in vivo. These findings indicate that the cAMP-CREB cascade plays an important role in the differentiation and maturation of newborn neurons in hippocampus.
\end{abstract}

Key words: rolipram; phosphodiesterase type IV (PDE4); cAMP response element-binding protein (CREB); antidepressant; subgranular zone; dentate gyrus

\section{Introduction}

In the adult hippocampus, neurogenesis continues to occur throughout life and contributes to structural plasticity and hippocampal function, including learning and memory (Altman and Das, 1965; Shors et al., 2001; van Praag et al., 2002). Neural progenitor cells are located primarily in the subgranular zone (SGZ) of the dentate gyrus, at the border between the granule cell layer (GCL) and the hilus, where these cells proliferate and develop axons and dendrites that make synaptic contacts (Kaplan and Bell, 1984; Stanfield and Trice, 1988). The growth of neuronal processes, or structural maturation, is necessary for newborn neurons to participate in the function of the hippocampus; however, the cellular pathways contributing to the maturation process in newborn neurons of adult hippocampus have not been fully determined, despite the high degree of interest and number of studies investigating the regulation of adult proliferation in recent years (Cameron and Gould, 1994; Kuhn et al., 1996; Gould et al., 1997; van Praag et al., 1999; Eisch et al., 2000; Malberg et al., 2000).

\footnotetext{
Received April 10, 2003; revised October 31, 2003; accepted November 5, 2003.

This work is supported by United States Public Health Service Grants MH45481 and 2 P01 MH25642, by a Veterans Administration National Center Grant for post-traumatic stress disorder, and by the Connecticut Mental Health Center.

Correspondence should be addressed to Ronald S. Duman, 34 Park Street, New Haven, CT 06508. E-mail: ronald.duman@yale.edu.

DOI:10.1523/JNEUROSCI.1065.03.2004

Copyright $\odot 2004$ Society for Neuroscience $\quad$ 0270-6474/04/240319-10\$15.00/0
}

To date, very little information is available concerning the intracellular signal transduction pathways that regulate neurogenesis in the adult hippocampus. Recent studies, however, implicate the cAMP cascade and the cAMP response elementbinding protein (CREB). CREB is a member of the activating transcription factor family, and its activity requires phosphorylation at $\operatorname{Ser}^{133}$ (Montminy et al., 1990). We have reported that the cAMP-CREB cascade is one of the key signal transduction cascades involved in neuronal proliferation in the adult mouse hippocampus (Nakagawa et al., 2002a). In this study, we found that activation of the cAMP cascade by administration of rolipram, a selective inhibitor of cAMP-specific phosphodiesterase type 4 (PDE4), increased cell proliferation in the hippocampal dentate gyrus, and this effect was accompanied by activation of CREB phosphorylation; however, the influence of the CAMP-CREB cascade on the maturation of newborn neurons was not examined.

The maturation of neurons can be examined by immunohistochemical analysis of markers for immature neurons, such as TUC-2 (TOAD-64/Ulip/CRMP-2) and polysialic acid-neural cell adhesion molecule (PSA-NCAM). These markers are abundant in postmitotic neurons during development and subsequently decrease to low levels in the adult brain (Seki and Arai, 1991; Minturn et al., 1995). One brain region in which these markers of immature neurons persist in the adult brain is the SGZ of the dentate gyrus (Seki and Arai, 1991; Scott et al., 1998). Recent reports have demonstrated that phosphorylation of CREB in immature neurons increases their survival and is accompanied 
by increased levels of brain-derived neurotrophic factor (BDNF) (Bender et al., 2001; Nakagawa et al., 2002b). The elevated levels of activated CREB raise the possibility that the CAMP cascade could also contribute to the maturation of newborn neurons in adult hippocampus.

The present study investigates the effects of the cAMP-CREB cascade on the maturation of newborn neurons in the dentate gyrus by morphometric analysis of Golgi-impregnated cells. We use a combination of pharmacological and transgenic approaches in both in vivo and in vitro assays to determine the influence of cAMP and CREB on neuronal maturation and morphology. We report that the CAMP-CREB cascade enhances the morphological maturation of newborn neurons in adult hippocampus.

\section{Materials and Methods}

Animals: transgenic mice. Male C57BL/6 mice, 8-10 weeks of age (Charles River Laboratories, Wilmington, MA) housed under a $12 \mathrm{hr}$ light/dark cycle with food and water ad libitum were used in the present study. The procedures using animals were in accordance with the National Institutes of Health Guide for the Care and Use of Laboratory Animals and were approved by the Yale University Animal Care and Use Committee. To elucidate the role of CREB in the actions of rolipram, we also used inducible transgenic mice expressing a dominant-negative phosphorylation mutant of CREB (mCREB) under the control of tetracycline-regulated promoter. The method for generating transgenic mice with inducible and brain region-specific $\mathrm{mCREB}$ expression has been described in detail in previous studies (Chen et al., 1998; Nakagawa et al., 2002a; Newton et al., 2002). Bi-transgenic or single transgenic mice were reared with the tetracycline analog doxycycline in the drinking water. After weaning, doxycycline was removed from the drinking water to allow for induction of mCREB expression, and animals were used at 8-10 weeks of age. All transgenic mice used in this study were maintained in strict accordance with National Institutes of Health and institutional animal care guidelines.

Experimental treatment procedures. For all in vivo experiments, bromodeoxyuridine (BrdU) ( 75 mg/kg, i.p.; Sigma, St. Louis, MO) was administrated once daily for $3 \mathrm{~d}$ to label proliferating cells. In the experiments that examine CREB phosphorylation in newborn neurons, mice were investigated on $3,7,14$, and $21 \mathrm{~d}$ after BrdU injection. In the rolipram experiment, rolipram ( $1.25 \mathrm{mg} / \mathrm{kg}$, i.p.; Sigma) in saline containing $2 \%$ dimethyl sulfoxide or the vehicle alone was administrated. For the experiment examining the effect of rolipram on the morphology of Golgi-impregnated immature neurons in the SGZ, C57BL/6 and transgenic mice were treated daily with rolipram or the vehicle for 2 weeks. For the effect of rolipram on CREB phosphorylation, mice were injected with vehicle or rolipram for 3,7 , or $14 \mathrm{~d}$ and perfused $2 \mathrm{hr}$ after the last injection for immunohistochemistry.

Golgi staining. Twenty-four hours after rolipram treatment (2 weeks), C57BL/6 or bi-transgenic mice were perfused transcardially with a solution of $0.1 \mathrm{~m}$ phosphate buffer containing $4 \%$ paraformaldehyde, $\mathrm{pH} 7.4$, under deep anesthesia (Nembutal; $100 \mathrm{mg} / \mathrm{kg}$, i.p.). After the intact brains were removed, one hemisphere of each brain was incubated in $1 \%$ potassium dichromate, $1 \%$ mercury chloride, $0.8 \%$ potassium chromate, and $0.5 \%$ potassium tungstate in distilled water in the dark at $4^{\circ} \mathrm{C}$ for 3 weeks. After the brains were rinsed with distilled water, they were incubated in $1 \%$ lithium hydroxide and $15 \%$ potassium nitrate in distilled water in the dark at $4^{\circ} \mathrm{C}$ for $5 \mathrm{~d}$. Brains were cut for analysis in $60-\mu \mathrm{m}$ thick coronal sections with a microtome set at $-15^{\circ} \mathrm{C}$.

Immunohistochemistry. After all mice were deeply anesthetized with Nembutal (100 mg/kg, i.p.), they were perfused in the same way as in the Golgi experiment. The brains were removed and postfixed overnight at $4^{\circ} \mathrm{C}$. After dehydration with sucrose solution, $30-\mu \mathrm{m}$-thick coronal sections of brains were cut with a microtome set at $-25^{\circ} \mathrm{C}$. The sections were incubated in the buffer containing $50 \%$ formamide and $2 \times$ standard saline citrate (SSC) solution $(0.3 \mathrm{M} \mathrm{NaCl}$ and $0.03 \mathrm{~m}$ sodium citrate) at $65^{\circ} \mathrm{C}$ for $1 \mathrm{hr}$. After washing with $2 \times$ SSC solution, the sections were incubated in $2 \mathrm{~N} \mathrm{HCl}$ at $37^{\circ} \mathrm{C}$ for $30 \mathrm{~min}$ and $0.1 \mathrm{M}$ boric acid, $\mathrm{pH} 8.5$, for 10 min. After blocking nonspecific binding with 3\% normal donkey serum for $40 \mathrm{~min}$, the brain sections were incubated with rat antiserum against BrdU (1:100; Harlan Sera Lab, Loughborough, UK), rabbit antiserum against TUC-2 (1:1000; kindly provided by Dr. S. Hockfield, Yale University, New Haven, CT), mouse antiserum against CREB (1:200; Zymed Laboratories, South San Francisco, CA), and goat antiserum against phosphorylated CREB (pCREB) (1:100; Santa Cruz Biotechnology, Santa Cruz, CA). After washing with PBS, sections were incubated with donkey anti-rat IgG labeled with Cy5 (1:100; Jackson ImmunoResearch, West Grove, PA), donkey anti-rabbit IgG labeled with FITC (1: 200; Jackson ImmunoResearch), donkey anti-mouse IgG labeled with Cy3 (1:200; Jackson ImmunoResearch), and donkey anti-goat IgG labeled with Cy3 (1:200, Jackson ImmunoResearch) for 2 hr. Fluorescent preparations were evaluated with the aid of confocal laser microscopy (Zeiss LSM510, Oberkochen, Germany). To determine the level of CREB activation in the newborn neurons, the number of pCREBimmunoreactive cells in all newborn neurons that are both TUC-2 and BrdU immunopositive in the SGZ was determined in two sections from each of six mice in each experimental group.

Hippocampal primary culture. To investigate the direct effects of the cAMP cascade on the differentiation of newborn neurons, primary cultures of hippocampus were performed. To identify newborn neurons, $\mathrm{BrdU}$ was injected into neonatal mice $2 \mathrm{hr}$ before the procedure of primary culture. After anesthesia with Nembutal, the hippocampus was removed and dissociated mechanically. After incubation in DMEM (Invitrogen, Carlsbad, CA) with $0.25 \%$ trypsin (Invitrogen) for $10 \mathrm{~min}$ at $37^{\circ} \mathrm{C}$, the hippocampus was triturated with a plastic pipette to dissociate the tissue into single cells. After centrifugation (2000 rpm for $5 \mathrm{~min}$, three times), the cell pellet was resuspended in DMEM solution containing $10 \%$ heat-inactivated fetal bovine serum (Invitrogen), insulin $(5 \mu \mathrm{g} / \mathrm{ml}$; Sigma), penicillin (100 U/ml; Invitrogen), and streptomycin $(100 \mu \mathrm{g} / \mathrm{ml}$; Invitrogen). Dissociated hippocampal cells were plated at a density of $5 \times$ $10^{4}$ cells per square centimeter onto culture slides (Becton Dickinson, Franklin Lakes, NJ) precoated with poly-L-lysine (Sigma). Hippocampal primary cultures were treated with vehicle or a cAMP agonist (Sp-cAMP, BIOLOG, Bremen, Germany) or inhibitor (Rp-cAMP, BIOLOG) for $4 \mathrm{~d}$. Cultures were maintained at $37^{\circ} \mathrm{C}$ in a humidified $5 \% \mathrm{CO}_{2}$ atmosphere. After fixation with $4 \%$ paraformaldehyde, immunohistochemistry to identify newborn neurons was performed in the same way as conducted for hippocampal sections. Five dishes pooled from three independent cultures were used for analysis. In addition, to examine the effect of cAMP analogs on the activation of CREB in cultured newborn neurons, immunohistochemistry was performed after incubation with cAMP analogs for $2 \mathrm{~d}$. Fifty newborn neurons from each of the five dishes (for a total of 250 cells) that were both TUC-2 and BrdU positive were randomly selected for analysis. Five dishes in each experimental group, from three independent cultures, were analyzed for the expression of pCREB in newborn neurons.

Morphometric analysis. After the slides containing hippocampal sections and primary cultured cells were scanned by light microscopy (Zeiss) outfitted with a CCD camera, the results of these experiments were analyzed by the NIH Image software (Wayne Rasband, NIH, Bethesda, MD). All slides were coded before quantitative analysis, and the code was not broken until the analysis was completed. Golgiimpregnated neurons in the SGZ of the hippocampal dentate gyrus were selected for analysis on the basis of the following strict selection criteria as used in a modified version of a previous report (Gould et al., 1990). (1) the Golgi-impregnated cells must be located in the SGZ of the hippocampal dentate gyrus, where newborn-immature neurons are primarily found; the SGZ is defined as the layer of cells between the GCL and the hilus; (2) only Golgi-impregnated cells with one primary dendrite extending from the cell body were selected, because these cells are reported to be less mature than cells with multiple primary dendrites (Green and Juraska, 1985; Claiborne et al., 1990; Wang et al., 2000); (3) only cells with dark and consistent impregnation throughout the extent of all of the processes were chosen; (4) cells must be relatively isolated from neighboring impregnated neurons that could interfere with analysis. In addition to analysis of SGZ-labeled cells, we also analyzed a group of Golgi- 

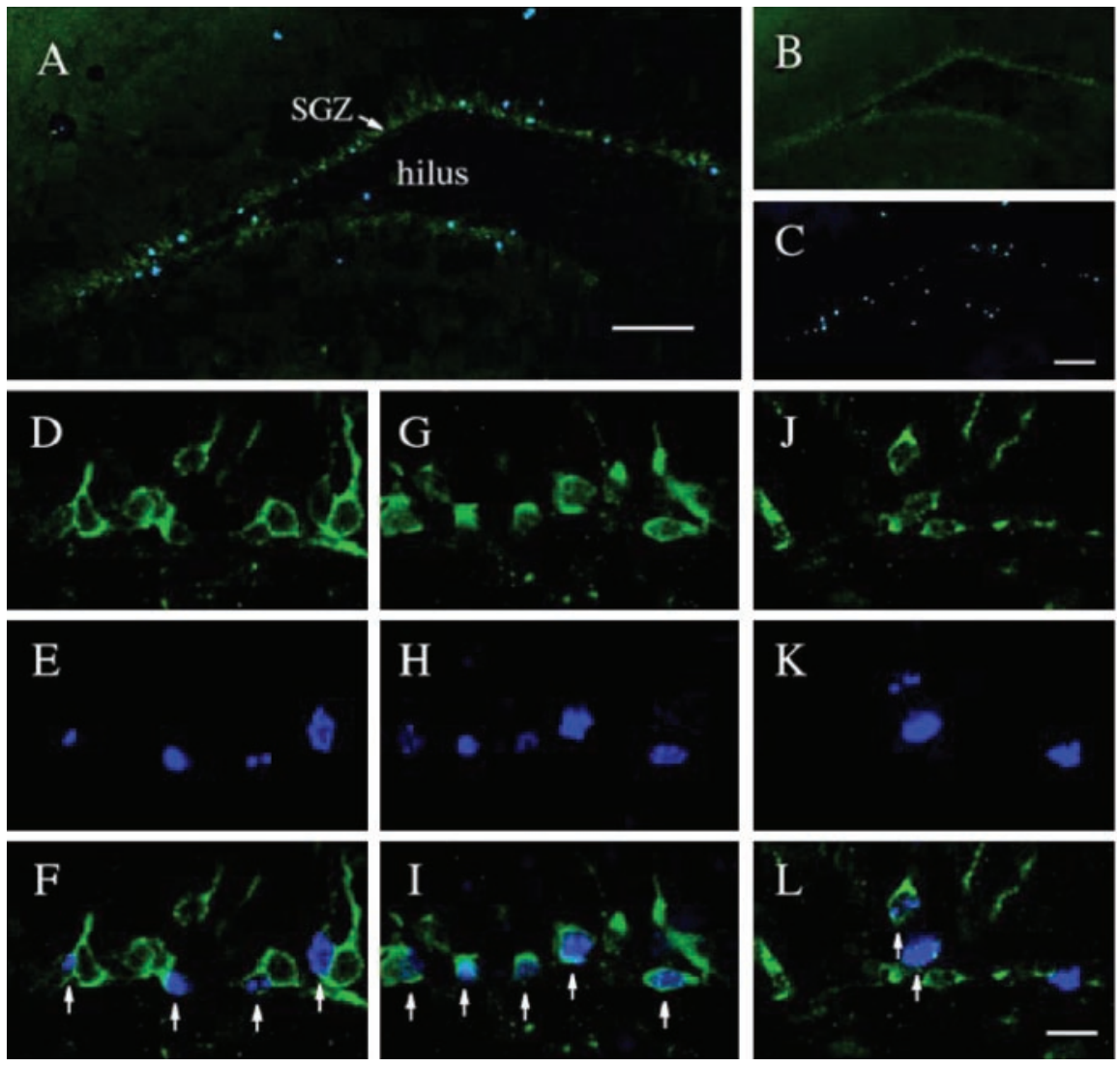

Figure 1. Distribution of TUC-2 and BrdU double-labeled cells in the adult dentate gyrus. Mice were administered BrdU, and $7 \mathrm{~d}$ $(A-F), 14 \mathrm{~d}(\mathrm{G}-l)$, or $21 \mathrm{~d}(J-L)$ later the brains were processed for TUC-2 and BrdU double immunohistochemistry. Shown are representative images of TUC-2 (green; $B, D, G, J$ ), BrdU (blue; $C, E, H, K)$, and the merged images $(A, F, I, L)$. Both TUC-2- and BrdU-immunoreactive cells are localized primarily within or adjacent to the $S G Z$ of the dentate gyrus, the border region between the $\mathrm{GCL}$ and hilus. Most of the BrdU-immunoreactive cells are also positive for TUC -2 immunoreactivity (arrows). TUC- 2 and BrdU double-labeled cells at 7-14 d of age were abundant in or adjacent to the SGZ $(F, I)$, whereas many double-labeled cells at $21 \mathrm{~d}$ were found above the SGZ. Scale bars: $A, C, 100 \mu \mathrm{m} ; L, 10 \mu \mathrm{m}$.

stained neurons that are located in the GCL and have one primary dendrite. Because of their location in the GCL, these neurons are considered more mature than those neurons located in the SGZ.

For each brain, all Golgi-impregnated neurons in the SGZ with one primary dendrite were analyzed from five sections taken at the level of the middle one-third of the hippocampus, according to the coordinates taken from Paxinos and Franklin (2001). The total length of the dendrites and the number of their branch points were measured. In addition, we analyzed much younger SGZ neurons, which were defined by a smaller dendritic tree that was limited to the GCL. These younger cells do not extend dendrites into the molecular layer where the major inputs for granule cells comes from the perforant fibers (Hjorth-Simonsen and Jeune, 1972; Steward, 1976). The average length and number of branch points from each animal were calculated, and then the mean \pm SEM for the control and rolipram-treated groups was determined. A similar approach was taken for each subpopulation of cells analyzed, including the total number of immature neurons in the SGZ, the younger immature neurons in the SGZ, and the mature neurons in the GCL.

In primary cultures of hippocampus, newborn neurons colabeled with TUC-2 and BrdU were subjected to morphometric analysis. The morphology was visualized by the expression of TUC-2. Newborn neurons relatively isolated from neighboring cells that could interfere with analysis were selected for analysis. The accuracy of the morphological analysis of TUC-2-immunoreactive neurons was confirmed under a phasecontrast microscope. Because the TUC-2-positive neurons display immunoreactivity in both the dendrites and the axons, all processes were analyzed without discerning the dendrites from the axons. Five dishes pooled from three independent experiments were used for analysis. Ten newborn neurons colabeled with TUC-2 and BrdU in each dish were randomly selected, for a total of 50 different cells per condition. The average length and number of dendrites of 10 cells in each dish were determined, and then mean \pm SEM of the five plates was determined.

Statistical analysis. All data are expressed as mean \pm SEM, and the results were analyzed by one-way factorial ANOVA followed by the Fisher's PLSD post hoc test, and comparisons between two groups were performed using the unpaired Student's $t$ test. The level of significance for all analysis was set at $p<0.05$ and 0.01 .

\section{Results}

Distribution of newborn, immature neurons in the adult hippocampal dentate gyrus

We examined the distribution of newborn neurons in the dentate gyrus during maturation. Newborn neurons were identified by double immunolabeling for TUC-2, a marker of immature neurons that has been implicated in axonal outgrowth and guidance (Quinn et al., 1999), and BrdU, a marker of proliferating cells. TUC-2 is a useful marker during early immature stages when neurons do not express any mature neuronal markers such as neuronal-specific nuclear marker (NeuN) or MAP2 (microtubule-associated protein 2) (Cameron et al., 1993; Seki, 2002). TUC-2 immunoreactivity was observed primarily in cell bodies, dendrites, and axons, and TUC-2-positive cells were found predominantly within or adjacent to the SGZ of the hippocampal dentate gyrus, at the border between the GCL and the hilus (Fig. $1 B, D, G, J$ ). Most of the BrdUimmunoreactive cells were also seen within or adjacent to the SGZ (Fig. $1 C, E, H, K$ ), and most, but not all, cells were colabeled with TUC-2 (Fig. $1 F, I, L$ ). These results are consistent with previous reports that the majority of newborn BrdU-positive cells ( $\sim 80 \%)$ express neuronal markers (van Praag et al., 1999; Nakagawa et al., 2002a). In addition, preliminary studies indicate that $\sim 70 \%$ of all cells in the SGZ are TUC-2-immunopositive cells, suggesting that most cells in this region of the dentate gyrus are immature neurons.

The age of newborn neurons was determined by the interval between the time point of the last BrdU injection and the time point of the perfusion of mice for immunohistochemistry. At the 7 and $14 \mathrm{~d}$ time points, TUC- 2 and BrdU colabeled neurons were abundant in or adjacent to the SGZ (Fig. $1 F, I$ ), whereas older TUC-2 and BrdU colabeled neurons (21 d) were frequently found above the SGZ of the GCL (Fig. 1L). These findings are consistent with previous studies demonstrating that newborn neurons in the SGZ migrate into the GCL as they mature (Cameron et al., 1993; Gage, 2000).

Expression of phosphorylated CREB in immature neurons of adult dentate gyrus

CREB requires phosphorylation at $\mathrm{Ser}^{133}$ to activate transcription of genes containing a cAMP response element (Montminy et 

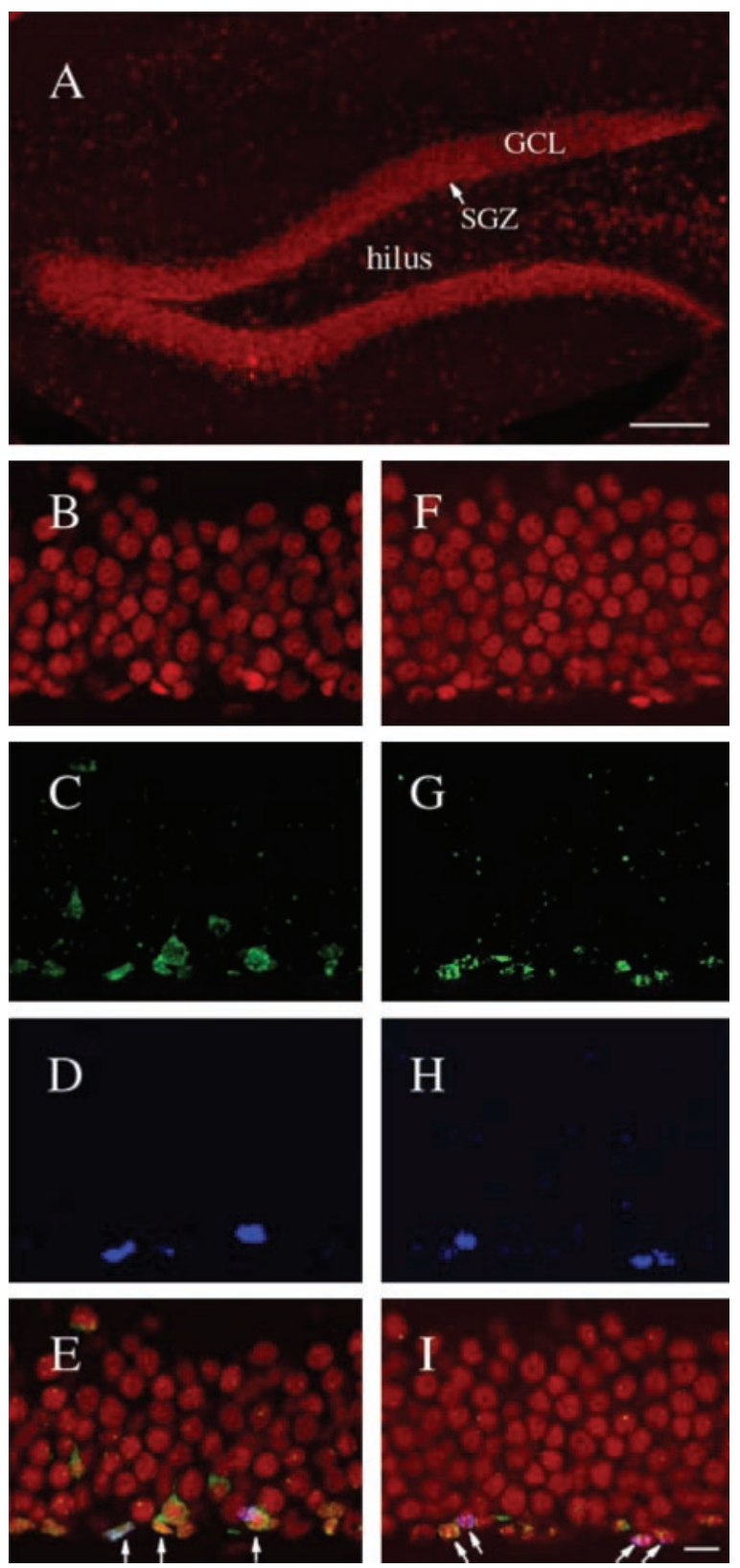

Figure 2. Analysis of CREB expression in the dentate gyrus of the adult hippocampus. Mice were administered $\mathrm{BrdU}$, and the brains were processed either $3 \mathrm{~d}(A-E)$ or $14 \mathrm{~d}(F-l)$ later for immunohistochemistry. Representative images of triple-immunostained cells are shown for CREB (red; $A, B, F$ ), TUC-2 (green; $C, G$ ), BrdU (blue; $D, H$ ), and the merged images $(E, I)$. A low-magnification image shows that CREB-immunoreactive cells are located throughout the entire GCL $(A)$. TUC-2- and BrdU-colabeled cells also expressed CREB immunoreactivity within or adjacent to the SGZ at both time points examined ( 3 and 14 d) (arrows). Scale bars: $A, 100$ $\mu \mathrm{m} ; \mathrm{l}, 10 \mu \mathrm{m}$.

al., 1990). In our previous studies, we found that the expression of CREB and pCREB-immunopositive cells was not distributed equally in the adult dentate gyrus in untreated animals. Although most cells throughout the GCL are CREB immunoreactive, only cells within or near the SGZ are positive for PCREB expression (Nakagawa et al., 2002b; Thome et al., 2000). To determine the time course for the induction of CREB in newborn neurons, we examined the expression of CREB and pCREB from 3 to $14 \mathrm{~d}$ after BrdU administration. CREB immunoreactivity is observed in most newborn, TUC-2, and BrdU colabeled neurons at the time points examined, 3, 7, and $14 \mathrm{~d}$ after BrdU administration (Fig. 2) (data for day 7 is not shown), and the expression of pCREB was dependent on the age of newborn neurons. On day 3 pCREB expression was observed in $31.0 \pm 0.7 \%$ of newborn neurons, and the percentage of TUC-2 and BrdU colabeled neurons expressing pCREB significantly increased by 7 and $14 \mathrm{~d}$ (Fig. 3) $\left(F_{(2,15)}=167.6 ; p<0.01 ; n=6\right.$ in each group) $(7 \mathrm{~d}, 59.5 \pm 3.6$; $14 \mathrm{~d}, 89.1 \pm 1.4)$. Previous reports have demonstrated that levels of pCREB immunoreactivity decrease between 2 and 4 weeks of age as neurons mature and migrate into the GCL (Nakagawa et al., 2002b).

Activation of the CAMP-CREB cascade increases the length of dendrites and number of branch points of Golgi-impregnated neurons in the SGZ

Expression of pCREB during the 2 week period after cell birth in the SGZ of the hippocampus suggests that this transcription factor participates in the maturation of newborn neurons. To test this possibility, studies were conducted to determine whether activation of CREB contributes to the morphological maturation of neurons, as measured by the extension and branching of dendrites. The cAMP-CREB cascade was activated by administration of rolipram, a selective inhibitor of PDE4, which is reported to increase levels of pCREB in the hippocampus (Nakagawa et al., 2002a). The number of branch points and length of dendrites were determined by analysis of Golgi-impregnated neurons. Because most newborn immature neurons ( $\sim-14 \mathrm{~d}$ of age) are found in the SGZ (Figs. 1-3), we first examined only Golgiimpregnated cells within this region. In vehicle-treated controls, however, Golgi-impregnated neurons in the SGZ were found at various stages of differentiation (Fig. $4 \mathrm{~A}$ ), as indicated by the number of branch points and the total length of dendrites. To examine a more immature population of cells, we identified two populations of immature neurons in the SGZ and compared the morphology of these cells with a population of mature cells located in the GCL. Classification of the immature neurons in the SGZ is based on differences in dendritic morphology, specifically the number of primary dendrites extending from the cell body and the length of dendrites, as reported previously (Green and Juraska, 1985; Claiborne et al., 1990; Wang et al., 2000). Immature neurons have only one primary dendrite, whereas mature neurons have multiple primary dendrites. Therefore we analyzed only SGZ neurons with one primary dendrite. Rolipram administration for 2 weeks resulted in a significant increase in both the number of branch points ( $p<0.01$; rolipram, $3.7 \pm 0.3, n=8$; vehicle, $2.5 \pm 0.2, n=7$ ) and the total length (micrometers) of dendrites $(p<0.01$; rolipram, $236.7 \pm 21.2, n=8$; vehicle, $138.3 \pm 13.4, n=7$ ) (Fig. $4 B-D$ ).

In addition, we analyzed the youngest population of immature neurons in the SGZ. Relatively older immature neurons in the SGZ spread their dendrites into the molecular layer, whereas the youngest immature neurons have a smaller dendritic tree that does not extend into the molecular layer. Chronic rolipram treatment significantly increased the total length (micrometers) of dendrites ( $p<0.05$; rolipram, $33.0 \pm 2.1, n=8$; vehicle, $26.2 \pm$ $1.1, n=7$ ) but not the number of branch points (rolipram, $1.3 \pm$ $0.1, n=8$; vehicle, $1.2 \pm 0.1, n=7$ ) of these younger Golgistained cells (Fig. 4E,F).

Finally, we analyzed the morphology of mature granule cells located in the GCL, adjacent to the SGZ. Chronic administration of rolipram did not significantly influence either the number of branch points (rolipram, $6.3 \pm 0.3, n=8$; vehicle, $6.0 \pm 0.3, n=$ 7 ) or the total length (micrometers) of the dendrites (rolipram, $519.0 \pm 20.3, n=8$; vehicle, $516.0 \pm 27.3, n=7$ ) (Fig. $4 G, H)$. 

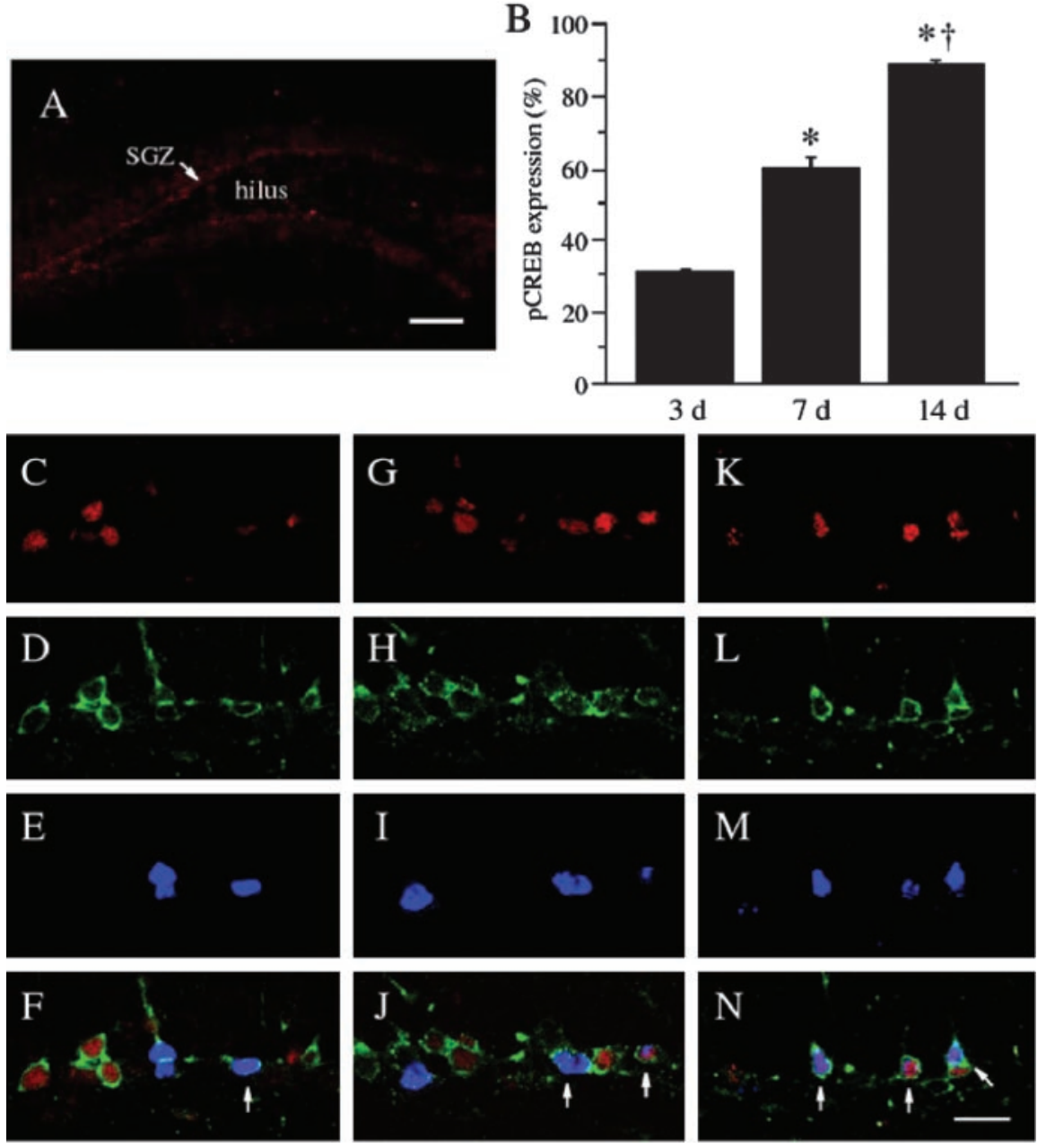

Figure 3. Analysis of $p C R E B$ immunoreactivity in maturing cells of adult hippocampus at different time points after birth. Mice were administered BrdU, and $p$ CREB immunoreactivity in the dentate gyrus was determined $3 \mathrm{~d}(A, C-F), 7 \mathrm{~d}(\mathrm{G}-J)$, or $14 \mathrm{~d}(K-N)$ later. Representative triple-immunostained images are shown for pCREB (red; $A, C, G, K$ ), TUC-2 (green; $D, H, L$ ), and BrdU (blue; $E, I, M)$, as well as for all three merged $(F, J, N)$. Images with low magnification show that $p C R E B$-immunoreactive cells are located mostly around the SGZ $(A)$. Expression of pCREB in newborn neurons with both TUC- 2 and BrdU immunoreactivity was increased with the age of labeled cells after BrdU administration (from 3 to $14 \mathrm{~d}$ ) (arrows). In the graph ( $B$ ), entries represent the mean \pm SEM percentage of $p$ CREB-immunoreactive cells in all newborn neurons at each age ( $n=6$ in each group). With age, the percentage of $p$ CREB-immunoreactive cells was significantly increased compared with that in younger cells $\left({ }^{*} p<0.01\right.$ as compared with the $3 \mathrm{~d}_{\text {group; }}{ }^{\dagger} p<0.01$ as compared with the $7 \mathrm{~d}$ group). Scale bars: $A, 100 \mu \mathrm{m} ; N, 10 \mu \mathrm{m}$.

Rolipram administration for 3 or $7 \mathrm{~d}$ significantly increased the rate of phosphorylation of CREB in newborn, TUC-2, and BrdU colabeled neurons in the SGZ $(3 \mathrm{~d}, 50.5 \pm 3.0, n=6 ; 7 \mathrm{~d}$, $73.1 \pm 2.0, n=6)$ compared with vehicle treatment $(3 \mathrm{~d}, 24.6 \pm$ $1.7, n=6 ; 7 \mathrm{~d}, 62.3 \pm 1.7, n=6$ ) (Fig. 5). There was no significant difference between the rolipram and vehicle groups after $14 \mathrm{~d}$ of administration (rolipram, $95.9 \pm 2.0, n=6$; vehicle, $90.9 \pm 2.7$, $n=6$ ) attributable to the near maximal levels of pCREB-positive cells under basal conditions at this later time point (Fig. 5).

Activation of CREB does not influence the maturation of SGZ neurons in transgenic mice expressing a dominant-negative mutant of CREB

To further evaluate the effect of the CAMP-CREB cascade on the differentiation of newborn neurons in response to rolipram, we used inducible transgenic mice that express a dominant-negative mutant form of CREB (Newton et al., 2002). Figure $6 A$ shows the strategy for making inducible transgenic mice using the tetracycline-off system. First, we developed one line of mice that contains the tetracycline transactivator (tTA) gene under the control of a $1.8 \mathrm{~kb}$ fragment of the neuron-specific enolase (NSE) promoter. A second line was generated in which a FLAG-tagged dominant-negative Ser ${ }^{133}$ to Ala mCREB gene was under the control of the tetracycline-operated promoter (TetOp). The FLAG-tag peptide is Asp-Tyr-LysAsp-Asp-Asp-Asp-Lys. This phosphorylation mutant of CREB can bind to genes containing a CRE but cannot be activated (Newton et al., 2002). The resulting NSEtTA $x$ TetOp-mCREB bi-transgenic mice were raised on a tetracycline analog until weaning to block expression of mCREB during development. Single TetOpmCREB transgenic mice have no expression of mCREB, demonstrating that there is no leak of the TetOp-mCREB gene (Chen et al., 1998; Nakagawa et al., 2002a; Newton et al., 2002). Mice were then raised in the absence of doxycycline for $\sim 6$ weeks to allow for the expression of FLAG-mCREB. Rolipram administration for 2 weeks, which facilitated the maturation of the SGZ neurons in wild-type mice, did not influence the number of branch points (rolipram, $2.5 \pm 0.1, n=6$; vehicle, $2.5 \pm 0.1, n=6$ ) or the total length (micrometers) of the dendrites (rolipram, $124.6 \pm 8.5, n=6$; vehicle, $132.6 \pm 10.9$, $n=6)$ in the bi-transgenic mice expressing mCREB (Fig. 6B, $C$ ).

A comparison of vehicle-treated wildtype mice versus FLAG-mCREB mice was also conducted. In the immature neurons with one primary dendrite, there was no significant difference between the wildtype and FLAG-mCREB transgenic mice (length in micrometers of dendrites: wildtype, $138.3 \pm 13.4, n=7$; FLAG-mCREB, $132.6 \pm 10.9, n=6$; number of branch points: wild type, $2.5 \pm 0.2, n=7$; FLAGmCREB, $2.5 \pm 0.1, n=6$ ). There was, however, a significant effect in the younger SGZ neurons, characterized by a smaller dendritic tree that does not extend into the molecular layer (Fig. $6 D)$. In the FLAG-mCREB mice there was a significant decrease in the total length (micrometers) of dendrites of these younger neurons ( $p<0.05$; wild type, $26.2 \pm 1.1, n=7$; FLAG-mCREB, $20.0 \pm 2.1, n=6$ ) but not in the number of branch points (wild type, $1.2 \pm 0.1, n=7$; FLAG-mCREB, $1.1 \pm 0.04, n=6$ ) relative to those in the wild-type mice (Fig. $6 D, E$ ). Finally, we analyzed mature Golgi-impregnated neurons located in the GCL and found no significant difference between the wild-type and mCREB mice in either the total length (micrometers) of dendrites (wild type, 516.0 $\pm 27.3, n=7$; FLAG-mCREB, $495.0 \pm$ 24.0, $n=6$ ) or number of branch points (wild type, $6.0 \pm 0.3, n=$ 7; FLAG-CREB, $5.6 \pm 0.3, n=6$ ) (Fig. $6 F, G$ ).

To examine the expression of $\mathrm{mCREB}$ in the newborn neurons in the bi-transgenic mice, we performed triple-labeling immunohistochemistry for TUC-2, BrdU, and FLAG- 
A

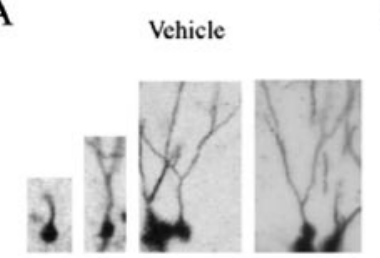

C

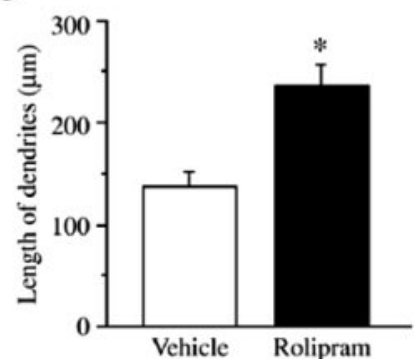

E

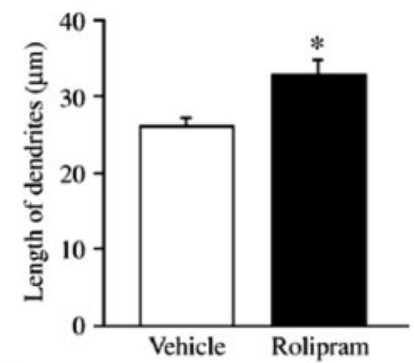

G

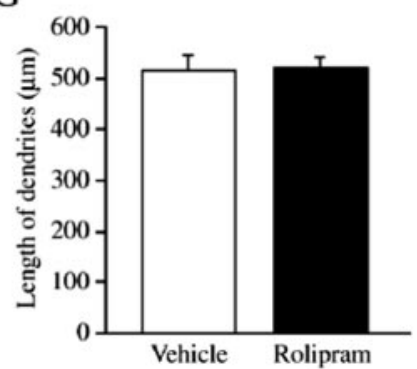

B

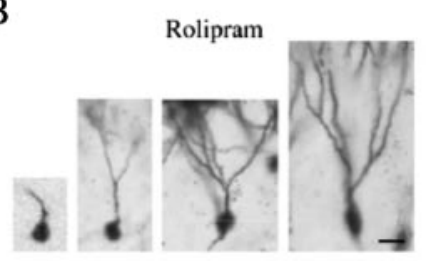

D

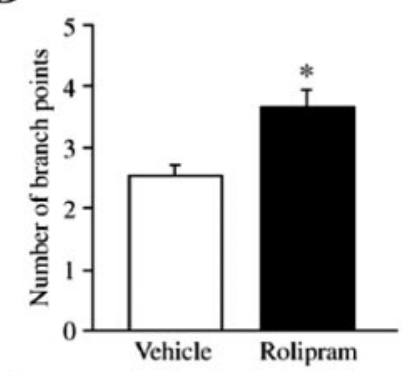

F

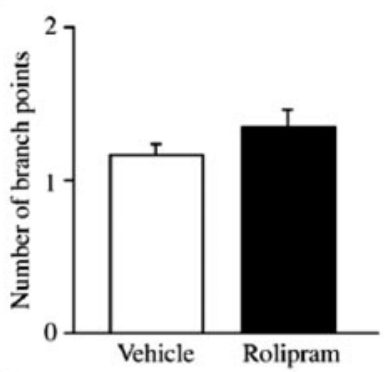

$\mathrm{H}$

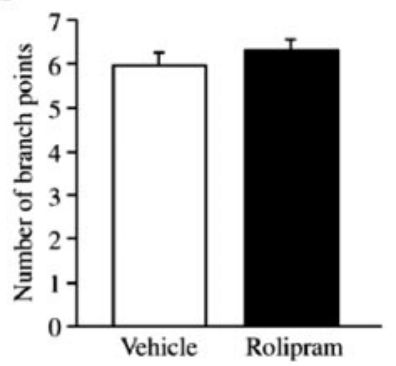

Figure 4. Effect of rolipram treatment on the morphology of Golgi-impregnated neurons in the SGZ of the adult hippocampus. Representative Golgi-impregnated SGZ neurons at different stages of maturation from vehicle and rolipram-treated mice are shown $(A, B)$. Differentiation of Golgi-impregnated neurons was observed as an increase in the total length and number of branch points of dendrites. In the graphs $(C-H)$, the results are presented as the mean \pm SEM dendrite length (micrometers) $(C, E, G)$ or number of branches $(D, F, H)$ (vehicle, $n=7$; rolipram, $n=8$ ). ( and $D$ show the results of all Golgi-impregnated cells in the SGZ neurons, demonstrating a significant increase in both the total length $(C)$ and number of branch points $(D)$ in rolipram-treated mice compared with those in vehicle-treated mice $\left.{ }^{* *} p<0.01\right)$. Eand F show the results of younger SGZ neurons, characterized by a smaller dendritic tree that does not extend to the molecular layer. Rolipram treatment significantly increased the total length $(E)\left({ }^{*} p<0.05\right)$ but not the number of branch points $(F)$ of these younger neurons. $G$ and $H$ show the analysis of mature neurons located in the $\mathrm{GCL}$. There was no significant effect of rolipram on the morphology of Golgi-impregnated cells in the $\mathrm{GCL}$. Scale bar: $B, 10 \mu \mathrm{m}$.

mCREB. FLAG-mCREB-immunoreactive cells were diffuse throughout the entire dentate gyrus. Many newborn neurons labeled with TUC-2 and BrdU in the SGZ of the bi-transgenic mice also expressed FLAG-mCREB. No FLAG immunoreactivity was observed in NSE-tTA single transgenic mice or TetOp-mCREB single transgenics (data not shown).

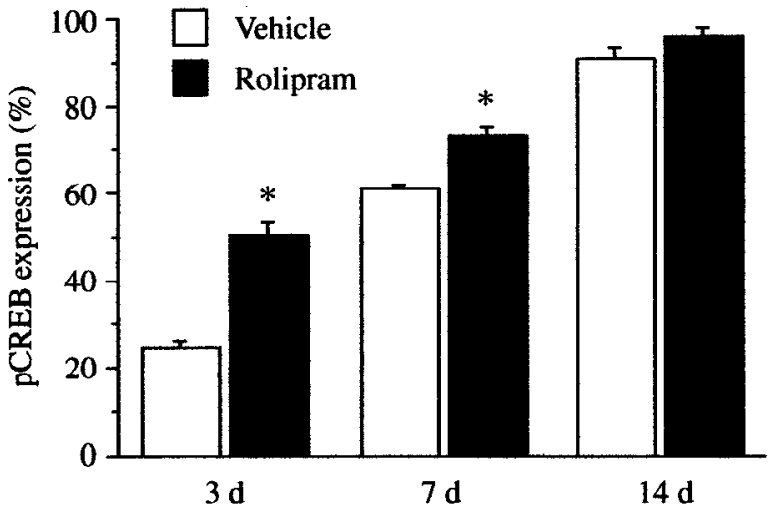

Figure 5. Effect of rolipram treatment on pCREB expression in newborn neurons in the SGZ of the adult hippocampus. Sections were subjected to triple-immunostaining for pCREB, TUC-2, and BrdU after vehicle and rolipram treatment for 3, 7, or $14 \mathrm{~d}$ as indicated. The percentage of newborn cells that are $\mathrm{pCREB}$ positive is presented as the mean \pm SEM ( $n=6$ animals per group). Rolipram treatment for 3 or $7 \mathrm{~d}$ significantly increased the percentage of $p$ CREB cells within or adjacent to the SGZ compared with vehicle treatment. There was no significant difference after $14 \mathrm{~d}$ of rolipram treatment $\left({ }^{*} p<0.01\right.$ as compared with the vehicle on each day).

\section{Activation of the CAMP-CREB cascade increases the maturation of newborn neurons in primary cultures of hippocampus}

Because the SGZ of the hippocampus contains newborn neurons at various stages of maturation (from $1 \mathrm{~d}$ to 2 weeks), we used primary cultures of hippocampus to examine the influence of the CAMP-CREB cascade on TUC-2 and BrdU colabeled, newborn neurons of approximately the same age (Fig. 7). BrdU was administered to 1-d-old neonatal mice, and then the hippocampus was harvested for primary cultures $2 \mathrm{hr}$ later, ensuring that all of the BrdU-labeled neurons were of approximately the same age. Primary cultures were then incubated with vehicle or a cAMP agonist (Sp-cAMP) or inhibitor (Rp-cAMP) for $4 \mathrm{~d}$. Newborn neurons colabeled with TUC-2 and BrdU were then subjected to morphometric analysis. In this case the morphology was visualized by the expression of TUC-2 (Fig. 7). Incubation of the cultured cells with Sp-cAMP significantly increased the number of branch points $\left(10^{-6} \mathrm{M}, 4.7 \pm 0.4, n=5 ; 10^{-7} \mathrm{M}, 4.4 \pm 0.4, n=\right.$ 5) relative to incubation with vehicle $(3.1 \pm 0.2 ; n=5)$ or RpcAMP incubation $\left(10^{-6} \mathrm{M}, 2.5 \pm 0.4, n=5 ; 10^{-7} \mathrm{M}, 3.0 \pm 0.3\right.$, $n=5)\left(F_{(4,20)}=8.3 ; p<0.01\right)$. Incubation with Sp-cAMP also increased the total length (micrometers) of processes of the TUC-2 and BrdU colabeled, newborn neurons $\left(10^{-6} \mathrm{M}, 153.3 \pm\right.$ $\left.9.1, n=5 ; 10^{-7} \mathrm{M}, 122.8 \pm 5.2, n=5\right)$ relative to vehicle $(87.5 \pm$ $8.4 ; n=5)$ or incubation with Rp-cAMP $\left(10^{-6} \mathrm{M}, 57.4 \pm 4.9, n=\right.$ $\left.5 ; 10^{-7} \mathrm{M}, 72.5 \pm 3.5, n=5\right)\left(F_{(4,20)}=35.2 ; p<0.01\right)$. In addition, the total length of processes was significantly decreased after incubation with the higher concentration $\left(10^{-6} \mathrm{M}\right)$ of RpcAMP (Fig. 7D). The percentage of cultured newborn neurons (TUC-2 and BrdU immunoreactive cells) that were pCREB immunoreactive was significantly increased by incubation with Sp-cAMP $\left(10^{-6} \mathrm{M}, 80.8 \pm 3.4, n=5 ; 10^{-7} \mathrm{M}, 28.4 \pm 4.1, n=5\right)$ relative to incubation with vehicle $(22.4 \pm 2.9 ; n=5)$ or RpcAMP groups $\left(10^{-6} \mathrm{M}, 5.4 \pm 2.1, n=5 ; 10^{-7} \mathrm{M}, 20.4 \pm 6.1, n=\right.$ $5)$. In contrast, the number of newborn neurons that were $\mathrm{pCREB}$ immunopositive after incubation with Rp-cAMP was significantly lower relative to the vehicle group $\left(F_{(4,20)}=52.9 ; p<\right.$ $0.01)$. Incubation with the cAMP analogs did not significantly influence the survival of the newborn neurons in culture (vehicle, $1.4 \pm 0.6$ per field; Sp-cAMP, $10^{-6} \mathrm{M}, 2.0 \pm 0.6$ per field; RpcAMP, $10^{-6} \mathrm{M}, 1.4 \pm 0.4$ per field; $n=4$ for each condition). 
A
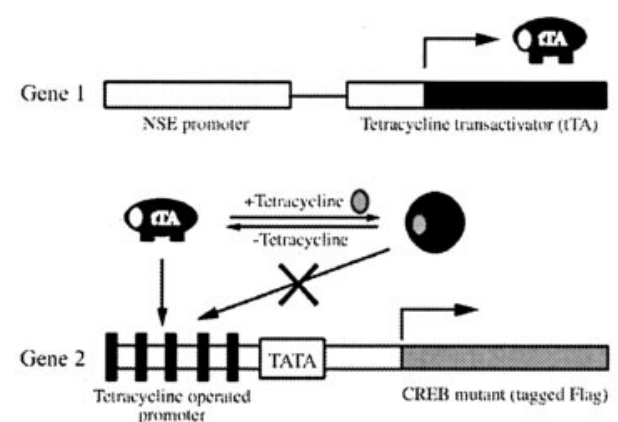

B

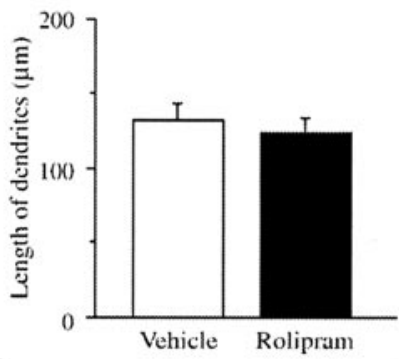

D

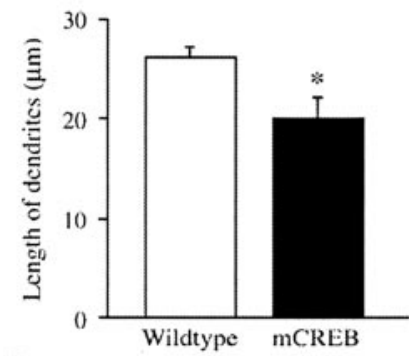

F

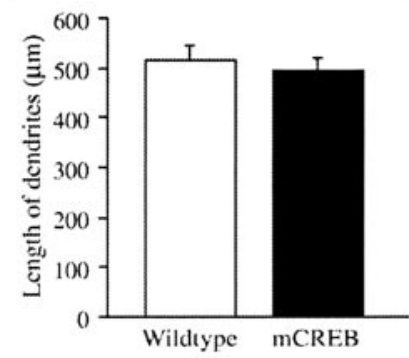

C

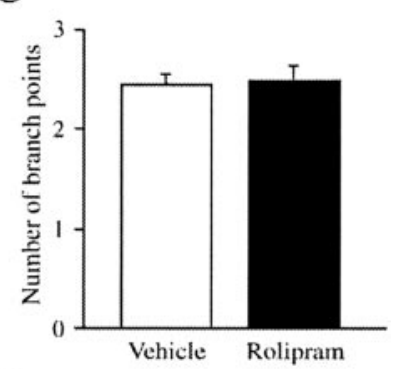

E

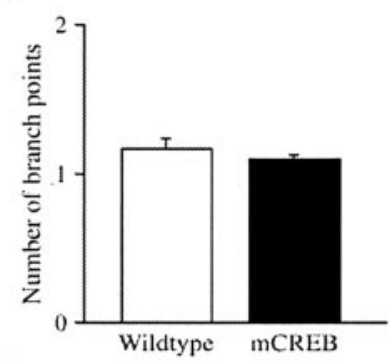

G

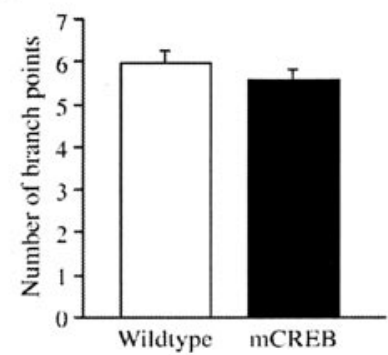

Figure 6. Effect of rolipram treatment on the morphology of Golgi-impregnated SGZ neurons in bi-transgenic mice expressing dominant-negative mCREB. Schematic diagram shows the strategy for development of inducible mCREB transgenic mice using the tetracycline-off system $(A)$. One line of mice contains the tTA gene under the control of a $1.8 \mathrm{~kb}$ fragment of the NSE promoter (gene 1). A second line of mice carries a FLAG-tagged mCREB construct, a Ser ${ }^{133}$ phosphorylation mutant, under the control of Tet0p. NSE-tTA x TetOp-mCREB bi-transgenic mice were obtained after crossbreeding these two lines to obtain a system for inducible expression of $m C R E B$. In the graphs $(B-G)$, the length of dendrites (micrometers) $(B, D, F)$ and number of branch points $(C, E, G)$ are presented as the mean \pm SEM. $B$ and $C$ show the results of all SGZ neurons, demonstrating that there was no significant difference between vehicle and rolipramtreated mice in either the total length of dendrites $(B)$ or number of branch points $(C)(n=6$ animals per group). $D-G$ compare the morphology of Golgi-impregnated neurons from vehicletreated wild-type mice versus FLAG-mCREB mice. $D$ and $E$ show the results of younger SGZ neurons (i.e., dendritic tree that does not extend into the molecular layer). In the FLAG-mCREB mice there was a significant decrease in the length of dendrites $(D)$ but not in the number of branch points $(E)$ of these younger neurons compared with those in the wild-type mice. Fand $G$ show the results of analysis of mature neurons located in the $\mathrm{GCL}$, demonstrating that there was no significant difference between the wild-type and FLAG-mCREB mice in this population of cells.

Taken together the results demonstrate that incubation with the cAMP agonist increases levels of pCREB and promotes the differentiation of cultured hippocampal newborn neurons, whereas incubation with the cAMP inhibitor suppresses levels of pCREB and neuronal differentiation.

\section{Discussion}

In this study we demonstrate that the CAMP-CREB cascade contributes to the maturation of newborn neurons in the adult hippocampus, in addition to increasing the proliferation and survival of these cells, as demonstrated in previous reports (Nakagawa et al., 2002a,b). Together, these studies demonstrate that the CAMP-CREB pathway plays a pivotal role in multiple aspects of neurogenesis in the adult hippocampus.

The evidence for the contribution of the cAMP-CREB cascade to the maturation of newborn neurons is supported by the following results. First, there is a spatial and temporal pattern of CREB phosphorylation that correlates with the maturation of newborn neurons. Phosphorylated CREB is observed primarily in the SGZ of the dentate gyrus where newborn immature neurons are located, and the expression of pCREB immunoreactivity in newborn neurons increases with age up to $14 \mathrm{~d}$ after proliferation. Second, activation of the CREB cascade by administration of rolipram facilitates the maturation of the SGZ neurons, and this effect is blocked in transgenic mice expressing a dominantnegative CREB mutant. Third, incubation of hippocampal primary cultures with a cAMP analog increases the arborization of newborn neurons, and this effect is accompanied by phosphorylation of CREB. In contrast, incubation with a cAMP inhibitor attenuates this morphological maturation and reduces levels of pCREB.

As the maturation of newborn neurons in the adult hippocampus proceeds, the expression of $\mathrm{pCREB}$ increases, and by 2 weeks nearly all newborn, TUC-2, and BrdU colabeled neurons are $\mathrm{pCREB}$ positive. A similar temporal pattern of pCREB expression has been observed during early postnatal development. Bender et al. (2001) have reported that pCREB expression in the GCL is minimal during the first postnatal week but is upregulated during the second and third weeks. In this study, the agedependent increase in levels of pCREB in the hippocampal GCL was not directly localized to newborn neurons during postnatal development. It has been estimated that $85 \%$ of the granule cells in the GCL are generated postnatally (Bayer, 1980), however, indicating that phosphorylation of CREB must be occurring primarily in newborn neurons. During this period, granule cells undergo prominent morphological maturation (Cowan et al., 1980; Amaral and Dent, 1981), supporting the proposed role of pCREB in the development of new granule cells.

The role of the CREB cascade during the critical period $(\sim 2$ weeks) of maturation of newborn neurons was investigated by quantitative analysis of Golgi-impregnated neurons as described previously (Duffy and Rakic, 1983; Williams and Matthysse, 1983; Green and Juraska, 1985; Gould et al., 1990). Although this technique results in random labeling of neurons, it is still considered a useful tool for morphometric studies. The morphology of Golgi-impregnated neurons in the SGZ was more variable than in the GCL where mature granule cells are located. In particular, Golgi-labeled neurons in the SGZ in general were less differentiated (fewer branch points and shorter dendrites) compared with GCL neurons (Fig. 4C,D, G,H), implying that the SGZ contains immature neurons at various stages of maturation. This finding is in accordance with previous reports that Golgi-impregnated granule cells in the superficial GCL exhibit a more differentiated 
morphology than those in the deeper GCL near the SGZ, although there has been no specific investigation of SGZ neurons (Duffy and Rakic, 1983; Green and Juraska, 1985). Because most newborn neurons remain in the SGZ for $\sim 2$ weeks, Golgi-impregnated neurons in the SGZ were assumed to be between $1 \mathrm{~d}$ and 2 weeks of age. The high density of TUC-2immunopositive cells in the SGZ provides further evidence that most of the cells in the region of the dentate gyrus are immature neurons. We cannot rule out the possibility, however, that a small percentage of the cells analyzed were mature neurons that are also influenced by regulation of the cAMP-CREB cascade. To address this point, we also examined the influence of rolipram on much younger neurons in the SGZ as well as mature neurons in the GCL. The results demonstrate that the maturation of the very immature neurons, but not the mature neurons, is enhanced by activation of the CAMP-CREB cascade.

The increased length of dendrites and the number of branch points of Golgiimpregnated neurons in the SGZ in response to rolipram administration indicates that there is an increase in the number of differentiated neurons compared with that after vehicle treatment. This indicates that activation of the cAMP_CREB cascade facilitates the development of newborn neurons. A role for CREB is supported by the finding that rolipram administration did not increase the length or number of dendrite branch points in bi-transgenic mice expressing a dominant-negative CREB mutant. Furthermore, in the dominant-negative CREB mutant mice we found that there was a significant reduction in the length of dendrites in the very young neurons in the SGZ relative to the wild-type controls. There was no significant difference in the morphology of the more mature neurons in the SGZ (i.e., those cells extending dendrites into the molecular layer) or the mature neurons in the GCL. The results are in agreement with the effects of rolipram in wild-type mice and provide further support that the CAMP-CREB pathway enhances the maturation of younger neurons in the SGZ but not mature neurons in the GCL. It is not clear why the more mature neurons in the SGZ are not influenced by mCREB. One possibility is that compensatory adaptations to the dominant-negative CREB take place and thereby mask the effects of MCREB on the continued maturation of neurons in the SGZ.

The contribution of the CREB cascade to the differentiation of newborn neurons was also confirmed using primary cultures of newborn hippocampal neurons. Newborn neurons in the hippocampus were labeled by injecting neonatal mice with BrdU $2 \mathrm{hr}$ before preparation of primary cultures. This allowed us to identify BrdU-labeled newborn neurons that were nearly identical in age. Using this system we found that incubation of primary cul-
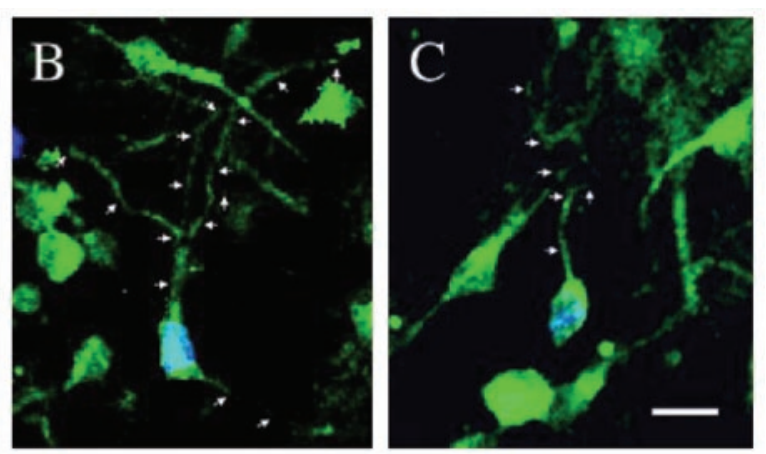

$\mathrm{E}$
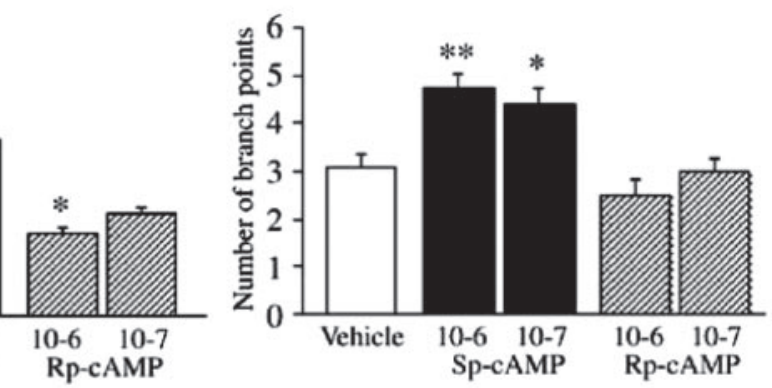

Sp-cAMP Rp-cAMP

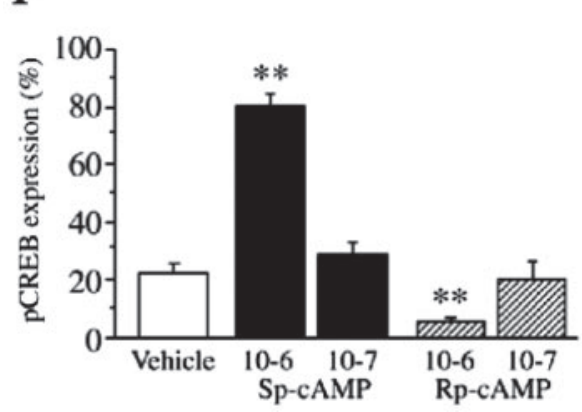

Figure 7. Effect of CAMP analogs on the maturation of newborn neurons in primary cultures of hippocampus. Representative

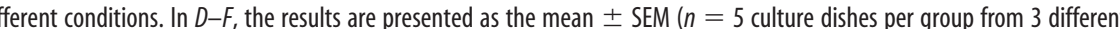
dose of Rp-cAMP had the opposite effect $(F) .{ }^{*} p<0.05 ;{ }^{* *} p<0.01$. Scale bar, $10 \mu \mathrm{m}$.

tures with a cAMP analog significantly enhanced the maturation of newborn neurons, whereas an inhibitor significantly decreased neuronal maturation. These in vitro results further demonstrate that activation of the CAMP-CREB cascade is necessary and sufficient for the maturation of newborn neurons. There was a discrepancy, however, between the induction of neuronal maturation and pCREB at the low dose of Sp-cAMP (Fig. 7D,F), suggesting that there is not a one-to-one correlation between these two endpoints. This could result from differences in the dose-response or time course for analysis of neuronal maturation and pCREB (e.g., $0.10 \mu \mathrm{M}$ Sp-cAMP could be a threshold dose or the induction of pCREB could be transient).

The possibility has been raised that neural stem cells may have therapeutic applications, particularly to replace damaged or dying neurons in neurodegenerative disorders (Gage, 2000). To achieve this goal it is necessary to characterize the factors that influence the proliferation and differentiation of neural stem 
cells. The results of this and our previous studies (Nakagawa et al., 2002a,b) demonstrate that the CAMP-CREB cascade is one of the key signal transduction pathways for regulation of neural stem cell proliferation and differentiation. These results are supported by a previous report demonstrating that incubation of cultured cells with forskolin, an activator of adenylyl cyclase and cAMP formation, increases the expression of $\mathrm{NeuN}$, a postmitotic marker of mature neurons (Palmer et al., 1997).

Although the target genes responsible for the actions of the CAMP-CREB cascade on the maturation of newborn neurons remain to be identified, two potential candidates are BDNF and PSA-NCAM. Both BDNF and PSA-NCAM play a role in synaptic plasticity and are reported to enhance the differentiation and survival of newborn neurons (Palmer et al., 1997; Bonni et al., 1999; Riccio et al., 1999; Amoureux et al., 2000). We have found that activation of the CAMP-CREB pathway increases the expression of BDNF in the hippocampus (Nibuya et al., 1996), and BDNF increases neurogenesis in adult brain (Benraiss et al., 2001; Pencea et al., 2001). The BDNF gene contains at least one cAMP response element in the exon III promoter that is regulated by CREB (Shieh et al., 1998; Tao et al., 1998). During postnatal development of the dentate gyrus, the expression of BDNF is observed during the period of granule cell maturation (postnatal days 7-21) and is coincident with the expression of pCREB (Bender et al., 2001).

Activation of CREB in newborn neurons also coincides with increased expression of PSA-NCAM (Nakagawa et al., 2002b). The formation of PSA-NCAM is controlled by a family of polysialic acid synthases that are rate limiting for PSA-NCAM formation. One of the synthases found in adult brain, referred to as ST8SiaII, contains a functional CRE, and transactivation of this promoter is regulated by CAMP and CREB (Nakagawa et al., $2002 \mathrm{~b}$ ). This suggests that activation of CREB increases levels of ST8SiaII-polysialic acid synthase and levels of PSA-NCAM in immature neurons. A link between pCREB, PSA-NCAM, and cell maturation is also supported by a study demonstrating that PSANCAM enhances the differentiation of newborn neurons (Amoureux et al., 2000). It is also likely that there are other growth factors and signaling molecules that are targets of CREB, and cDNA microarray studies are currently under way to identify additional gene targets.

Rolipram, the drug used to activate the cAMP-CREB cascade, is also reported to have antidepressant activity in both animal models and clinical trials (Wachtel, 1983; Zeller et al., 1984; Duman et al., 2000). Several different classes of antidepressants that are routinely prescribed for the treatment of depression are reported to increase granule cell proliferation and survival in the dentate gyrus (Madsen et al., 2000; Malberg et al., 2000; Nakagawa et al., 2002b). In addition, antidepressant administration activates the cAMP-CREB cascade (Nibuya et al., 1996; Thome et al., 2000). These findings suggest that the antidepressant efficacy of rolipram and the typical antidepressants occurs, in part, via regulation of neurogenesis. This hypothesis is supported by a recent study demonstrating that blockade of antidepressant induction of neurogenesis using either a mutant mouse model or irradiation blocks antidepressant efficacy in behavioral models of antidepressant activity (Santarelli et al., 2003). The results of the present study also suggest that the typical antidepressants, like rolipram, may increase the maturation of newborn neurons in the SGZ, a subject of current investigation. Together these results support the hypothesis that a drug that activates the cAMPCREB pathway would be an effective antidepressant agent.

\section{References}

Altman J, Das GD (1965) Autoradiographic and histological evidence of postnatal hippocampal neurogenesis in rats. J Comp Neurol 124:319-335.

Amaral DG, Dent JA (1981) Development of the mossy fibers of the dentate gyrus: I. A light and electron microscopic study of the mossy fibers and their expansions. J Comp Neurol 195:51-86.

Amoureux MC, Cunningham BA, Edelman GM, Crossin KL (2000) $\mathrm{N}$-CAM binding inhibits the proliferation of hippocampal progenitor cells and promotes their differentiation to a neuronal phenotype. J Neurosci 20:3631-3640.

Bayer SA (1980) Development of the hippocampal region in the rat. I. Neurogenesis examined with ${ }^{3} \mathrm{H}$-thymidine autoradiography. J Comp Neurol 190:87-114.

Bender RA, Lauterborn JC, Gall CM, Cariaga W, Baram TZ (2001) Enhanced CREB phosphorylation in immature dentate gyrus granule cells precedes neurotrophin expression and indicates a specific role of CREB in granule cell differentiation. Eur J Neurosci 13:679-686.

Benraiss A, Chmielnicki E, Lerner K, Roh D, Goldman SA (2001) Adenoviral brain-derived neurotrophic factor induces both neostriatal and olfactory neuronal recruitment from endogenous progenitor cells in the adult forebrain. J Neurosci 21:6718-6731.

Bonni A, Brunet A, West AE, Datta SR, Takasu MA, Greenberg ME (1999) Cell survival promoted by the Ras-MAPK signaling pathway by transcription-dependent and -independent mechanisms. Science 286:1358-1362.

Cameron HA, Gould E (1994) Adult neurogenesis is regulated by adrenal steroids in the dentate gyrus. Neuroscience 61:203-209.

Cameron HA, Woolley CS, McEwen BS, Gould E (1993) Differentiation of newly born neurons and glia in the dentate gyrus of the adult rat. Neuroscience 56:337-344.

Chen J, Kelz MB, Zeng G, Sakai N, Steffen C, Shockett PE, Picciotto MR, Duman RS, Nestler EJ (1998) Transgenic animals with inducible, targeted gene expression in brain. Mol Pharmacol 54:495-503.

Claiborne BJ, Amaral DG, Cowan WM (1990) Quantitative, threedimensional analysis of granule cell dendrites in the rat dentate gyrus. J Comp Neurol 302:206-219.

Cowan WM, Stanfield BB, Kishi K (1980) The development of the dentate gyrus. Curr Top Dev Biol 15:103-157.

Duffy CJ, Rakic P (1983) Differentiation of granule cell dendrites in the dentate gyrus of the rhesus monkey: a quantitative Golgi study. J Comp Neurol 214:224-237.

Duman RS, Malberg J, Nakagawa S, D’Sa C (2000) Neuronal plasticity and survival in mood disorders. Biol Psychiatry 48:732-739.

Eisch AJ, Barrot M, Schad CA, Self DW, Nestler EJ (2000) Opiates inhibit neurogenesis in the adult rat hippocampus. Proc Natl Acad Sci USA 97:7579-7584.

Gage FH (2000) Mammalian neural stem cells. Science 287:1433-1438.

Gould E, Woolley CS, McEwen BS (1990) Short-term glucocorticoid manipulations affect neuronal morphology and survival in the adult dentate gyrus. Neuroscience 37:367-375.

Gould E, McEwen BS, Tanapat P, Galea LA, Fuchs E (1997) Neurogenesis in the dentate gyrus of the adult tree shrew is regulated by psychosocial stress and NMDA receptor activation. J Neurosci 17:2492-2498.

Green EJ, Juraska JM (1985) The dendritic morphology of hippocampal dentate granule cells varies with their position in the granule cell layer: a quantitative Golgi study. Exp Brain Res 59:582-586.

Hjorth-Simonsen A, Jeune B (1972) Origin and termination of the hippocampal perforant path in the rat studied by silver impregnation. J Comp Neurol 144:215-232.

Kaplan MS, Bell DH (1984) Mitotic neuroblasts in the 9-day-old and 11month-old rodent hippocampus. J Neurosci 4:1429-1441.

Kuhn HG, Dickinson-Anson H, Gage FH (1996) Neurogenesis in the dentate gyrus of the adult rat: age-related decrease of neuronal progenitor proliferation. J Neurosci 16:2027-2033.

Madsen TM, Treschow A, Bengzon J, Bolwig TG, Lindvall O, Tingstrom A (2000) Increased neurogenesis in a model of electroconvulsive therapy. Biol Psychiatry 47:1043-1049.

Malberg JE, Eisch AJ, Nestler EJ, Duman RS (2000) Chronic antidepressant treatment increases neurogenesis in adult rat hippocampus. J Neurosci 20:9104-9110

Minturn JE, Geschwind DH, Fryer HJ, Hockfield S (1995) Early postmitotic 
neurons transiently express TOAD-64, a neural specific protein. J Comp Neurol 355:369-379.

Montminy MR, Gonzalez GA, Yamamoto KK (1990) Regulation of cAMPinducible genes by CREB. Trends Neurosci 13:184-188.

Nakagawa S, Kim JE, Lee R, Malberg JE, Chen J, Steffen C, Zhang YJ, Nestler EJ, Duman RS (2002a) Regulation of neurogenesis in adult mouse hippocampus by cAMP and the cAMP response element-binding protein. J Neurosci 22:3673-3682.

Nakagawa S, Kim JE, Lee R, Chen J, Fujioka T, Malberg J, Tsuji S, Duman RS (2002b) Localization of phosphorylated cAMP response elementbinding protein in immature neurons of adult hippocampus. J Neurosci 22:9868-9876.

Newton SS, Dow A, Terwilliger R, Duman R (2002) A simplified method for combined immunohistochemistry and in-situ hybridization in freshfrozen, cryocut mouse brain sections. Brain Res Brain Res Protoc 9:214-219.

Nibuya M, Nestler EJ, Duman RS (1996) Chronic antidepressant administration increases the expression of cAMP response element-binding protein (CREB) in rat hippocampus. J Neurosci 16:2365-2372.

Palmer TD, Takahashi J, Gage FH (1997) The adult rat hippocampus contains primordial neural stem cells. Mol Cell Neurosci 8:389-404.

Paxinos G, Franklin KBJ (2001) The mouse brain in stereotaxic coordinates, Ed 2. San Diego: Academic.

Pencea V, Bingaman KD, Wiegand SJ, Luskin MB (2001) Infusion of brainderived neurotrophic factor into the lateral ventricle of the adult rat leads to new neurons in the parenchyma of the striatum, septum, thalamus, and hypothalamus. J Neurosci 2:6706-6717.

Quinn CC, Gray GE, Hockfield S (1999) A family of proteins implicated in axon guidance and outgrowth. J Neurobiol 41:158-164.

Riccio A, Ahn S, Davenport CM, Blendy JA, Ginty DD (1999) Mediation by a CREB family transcription factor of NGF-dependent survival of sympathetic neurons. Science 286:2358-2361.

Santarelli L, Saxe M, Gross C, Surget A, Battaglia F, Dulawa S, Weisstaub N, Lee J, Duman R, Arancio O, Belzung C, Hen R (2003) Requirement of hippocampal neurogenesis for the behavioral effects of antidepressants. Science 301:805-809.

Scott BW, Wang S, Burnham WM, De Boni U, Wojtowicz JM (1998) Kindling-induced neurogenesis in the dentate gyrus of the rat. Neurosci Lett 248:73-76.
Seki T (2002) Expression patterns of immature neuronal markers PSANCAM, CRMP-4 and NeuroD in the hippocampus of young adult and aged rodents. J Neurosci Res 70:327-334.

Seki T, Arai Y (1991) The persistent expression of a highly polysialylated NCAM in the dentate gyrus of the adult rat. Neurosci Res 12:503-513.

Shieh PB, Hu SC, Bobb K, Timmusk T, Ghosh A (1998) Identification of a signaling pathway involved in calcium regulation of BDNF expression. Neuron 20:727-740.

Shors TJ, Miesegaes G, Beylin A, Zhao M, Rydel T, Gould E (2001) Neurogenesis in the adult is involved in the formation of trace memories. Nature 410:372-376.

Stanfield BB, Trice JE (1988) Evidence that granule cells generated in the dentate gyrus of adult rats extend axonal projections. Exp Brain Res 72:399-406.

Steward O (1976) Topographic organization of the projections from the entorhinal area to the hippocampal formation of the rat. J Comp Neurol 167:285-314.

Tao X, Finkbeiner S, Arnold DB, Shaywitz AJ, Greenberg ME (1998) $\mathrm{Ca}^{2+}$ influx regulates BDNF transcription by a CREB family transcription factor-dependent mechanism. Neuron 20:709-726.

Thome J, Sakai N, Shin K, Steffen C, Zhang YJ, Impey S, Storm D, Duman RS (2000) cAMP response element-mediated gene transcription is upregulated by chronic antidepressant treatment. J Neurosci 20:4030-4036.

van Praag H, Kempermann G, Gage FH (1999) Running increases cell proliferation and neurogenesis in the adult mouse dentate gyrus. Nat Neurosci 2:266-270.

van Praag H, Schinder AF, Christie BR, Toni N, Palmer TD, Gage FH (2002) Functional neurogenesis in the adult hippocampus. Nature 415:1030-1034.

Wachtel H (1983) Potential antidepressant activity of rolipram and other selective cyclic adenosine $3^{\prime}, 5^{\prime}$-monophosphate phosphodiesterase inhibitors. Neuropharmacology 22:267-272.

Wang S, Scott BW, Wojtowicz JM (2000) Heterogeneous properties of dentate granule neurons in the adult rat. J Neurobiol 42:248-257.

Williams RS, Matthysse S (1983) Morphometric analysis of granule cell dendrites in the mouse dentate gyrus. J Comp Neurol 215:154-164.

Zeller E, Stief HJ, Pflug B, Sastre-y-Hernandez M (1984) Results of a phase II study of the antidepressant effect of rolipram. Pharmacopsychiatry 17 : $188-190$. 